\title{
All together now: A symphony orchestra audience as a consuming community
}

\begin{abstract}
This study examines the nature of communal consumption in the context of audience experience of the performing arts. Building on existing literature on consumption communities and ritualistic perspectives on shared event-based consumption it uses focus groups and participant observation to investigate the experience of members of a UK symphony orchestra's audience as a consuming community (a "consumity" in short). It finds tensions between respondents' perceptions of their individual and collective experience, framed within a pervasive anxiety about the sustainability of both audience and art form. It concludes that the communal aspect of audience experience is more complex and inflected than current notions of shared consumption acknowledge, in particular with respect to the audience's sense of itself over time. It concludes by questioning the absence from current arts marketing discourse of a more integrated view of the experience of customers in a temporal context.
\end{abstract}

\section{Keywords}

Audience, classical music, consumption community, consumity, focus groups.

Terry O'Sullivan is senior lecturer in marketing at the Open University Business School. Correspondence to: Dr Terry O'Sullivan, The Open University Business School, Walton Hall, MILTON KEYNES MK7 6AA United Kingdom.

The author would like to thank the referees for their helpful comments. 


\section{Introduction}

The objective of this study is to explore the nature of communal consumption in the context of audience experience of the performing arts. What can arts audiences, as 'communities of consumption', tell us about the possibilities, conditions and implications of communal consumption both in the arts and, by extension, in other service sectors? And to what extent can concepts such as 'brand community' (Muniz Jr. and O'Guinn 2001) or the 'linking value of consumption' (Cova 1997) help us to understand communal acts of consumption such as those which occur at performances and other spectacles? What tensions exist, for example, between audience members as individuals and as a collective entity in how they experience performance? What does a communal act of consumption feel like? This paper builds upon key literature on consumption in a communal context with a qualitative investigation of audience experience of classical music to address these questions.

The classic microeconomic account of consumption focuses on value-maximising individuals or households considered as individual units - collective consumption being associated only with exceptional cases like 'public goods' such as sanitation and defence (Malinvaud 1972). We tend to think of consumption as something privatised and even in competition with collective interests -- witness the dialectic between notions of 'consumer' and 'citizen' in the marketisation of public services which has engaged many European administrations over the last two decades (Clarke et al. 2007). Furthermore 
All together now: A symphony orchestra audience as a consuming community

marketing has traditionally interpellated its subjects as individuals in its key discourses of promotion and selling. Responsibility for most purchases rests with individuals in the areas of decision, purchase, payment, ownership and disposal (even for products and services such as food, rented accommodation and holidays which are consumed by or with others). This is particularly true of quintessentially contemporary products and services such as mobile phones and computer software licensed to named individuals.

Academic criticism of marketing's isolation of the consumer (e.g, Lasch 1991; Leiss, Kline and Jhally 1990; Putnam 2000) resonates with commonsense models of sensory experience which suggest that we can only access the world of phenomena as individuals - creating autonomous, and possibly irreconcilable, versions of events, even when experiencing them simultaneously with others. It follows that consumption must be on an individual, atomized level. Yet weighing against this is a tradition of social research which emphasises intersubjectivity - the creation of knowledge and experience 'between' people. This tradition argues that by sharing time and space, two or more individual social actors are able to grasp each other's consciousness and thus participate in what is going on in each other's minds (Schutz [1932] 1967; Smith 1998). There is also evidence that emotion (a contested concept amongst psychologists even in its individual manifestation) can operate at a group level in proportion to members' identification and level of sharing with the group (Smith et al. 2007). Performing-arts audiences, whose experience has been characterised as being at a 'supra-individual' level (Coppieters 1981) offer a promising avenue of enquiry into intersubjective consumption, 
particularly where emotion is involved (an aspect of their response to music frequently mentioned by audience members in the present research).

There has been relatively little academic marketing attention to the subject of communal consumption - the kind of collective experience which one might connect with religious, ceremonial or artistic processes. (Gainer 1995; Henry and Caldwell 2007; Turner 1974). The present paper's contribution is to augment this literature by exploring the experience of audience members as a consuming community (a 'consumity' in short) of participants in an intersubjective experience. The concept of 'communitas', developed by Turner (1974) building on earlier anthropology (van Gennep, 1960), expresses the submergence of individual into collective identity in ceremonial or ritual activity. It has already been adapted to theorise aspects of 'extraordinary experience' in services marketing (Arnould and Price 1993). Together with intersubjectivity, it offers a promising theoretical tool to help illuminate what is going on in audience reception of live performance.

The approach to social research which informs this paper is interpretive, but led by a rigorous approach to research design and qualitative data analysis. My development of conclusions from the data is a reflexive process which has taken account of my own presence in the research (both as researcher and audience member myself) and the theoretical perspectives (both positivist and interpretivist) which support previous work in this area. 


\section{From community to 'consumity'}

According to Fraering and Minor (2006), the American historian Boorstin first articulated the notion that consuming products and services could underpin community, finding evidence of the role of marketing and advertising in the formation of communities which, while admittedly weak and temporary, nevertheless achieved a national reach in nineteenth-century America, and for masses of uprooted immigrants 'became a characteristic American mode of acculturation' (1974, 147). The robustness of Boorstin's concept of consumption communities along lines of national culture was subsequently tested via groups of respondents from the US and Belgium, most of whom reported 'a certain sense of community in relation to others who share their consumption behaviours' (Friedman, Abeele and de Vos 1993, 53).

Friedman et al. recognised that consumption-based links are relatively stronger 'for commodities high on value-expressiveness', including clothing, accommodation and entertainment $(1993,57)$. More recent research has cast light on the organisation and behaviour of communities of consumption both in the real world and online (Schouten and McAlexander 1995; Kozinets 1999; Muniz Jr. and O'Guinn 2001). Such research has focused on high-involvement items such as cars, motorcycles and computers. But, as studies of the linking value of coffee consumption (Kozinets 2002), or chocolate spread (Cova and Pace 2006), exemplify, involvement is determined by consumers rather than product class, suggesting the difficulty of associating consumption communities with particular markets in any simple way. Nevertheless, marketing interest in the 
All together now: A symphony orchestra audience as a consuming community

phenomenon has been intense because of its perceived connection with consumer loyalty (Armstrong and Hagel 1996; Oliver 1999; McAlexander et al. 2003). This connection can work both to the advantage and the disadvantage of producers, as consumers develop autonomous perspectives on the meaning and value of brands. The sense of membership of a brand-based consumption community has been termed 'camaraderie' in subsequent research (Fraering and Minor 2006). The literature covers social or virtual gatherings (such as meets, conventions or internet activity) with an essentially communal aspect where togetherness is crucial to the experience. But essentially it deals with community as an agglomeration of consumers who may unite to savour or elaborate their enthusiasm for a particular brand or product, but whose actual consumption practices remain largely individual and asynchronous rather than being based in collective activity.

There has been an accompanying extension of interest in consumer behaviour research to the cultural context in which consumption takes place. Inevitably this has moved the focus from the individual actor of traditional marketing theory to a more situated, socially-relative view of the consumer spanning both personal and collective identities (identities critical to service experience for any customer, but particularly relevant to the experience of an audience member for a live performance). Building on the concept of neotribalism (Maffesoli 1996), an important component of this emerging research tradition of 'Consumer Culture Theory' has investigated how 'consumers forge feelings of social solidarity and create distinctive, fragmentary, self-selected and sometimes transient cultural worlds through the pursuit of common consumption interests' (Arnould and Thompson 2005). 
Fragmentary and transient though such linkages are (Granovetter, 1973), contemporary marketing thought sees them as potentially more valuable to consumers than the products and services which underlie them (Cova 1997; Bohé 2007). Cova claims 'the link is more important than the thing', that the relational benefits which products or services deliver, or facilitate, has superseded their more obviously functional performance leading marketing researchers to analyse economic activity as 'embedded in a societal context which, at the same time, encompasses it and renders it possible' (1997, 314). But the ability of marketing organisations to leverage the resulting value remains limited because of the dynamics of the networks which create it. The collective 'acts as a force that mediates and complicates the relationship between marketing organization and individual consumer' (Kozinets 1999, 259). Because of their closeness to audiences, performing arts organisations may be in a position to develop more productive customer relations than other service providers. Indeed, Kozinets' characterisation of the way that, facilitated by online communication, 'loyal consumers are increasingly creating their tastes together, as a community' (1999, 259) sounds just like what an audience does in the interval of a performance: evaluating quality together, negotiating consumption standards and determining joint meanings. Here we glimpse the 'consumity' at work, creating conditions of consumption for its members which actively mediate the experience available to each through an intersubjective process. This phenomenon transcends the asynchronous acts underlying Boorstin's original concept of consumption communities, moving closer to the kind of communal consumption observable in audience experience of live performance itself. 
Because services, especially the performing arts, are rendered to people by people, the entire community in collective acts of consumption will extend beyond consumers to the employees of the service provider. This dimension of the service experience, where there is a personal as well as an economic relationship between producer and consumer, has been described as 'communality', benefiting consumers through increased personalisation and extended social networks, and producers with some protection against the consequences of service failure (Goodwin 1996). Goodwin sees it on a continuum from disinterested friendship at one end to entirely economic exchange at the other. It evolves in the context of a consumer's relationship with a service provider (Fraering and Minor 2006). In a performing arts context, communality could be argued to exist on at least two levels - the first with the front of house staff of the venue (including box office, attendants and administrators) and the second with the performers themselves. It may be that audience members are at different stages on the communality scale with either group, depending on their familiarity with the venue and their prior experience of the art form.

Fraering and Minor (2006) characterise the affiliation felt between consumers with each other within a consumption community as 'camaraderie'. This too may operate on multiple levels - from intimacy with immediate companions and neighbours, to less direct fellow-feeling with the general audience. There have been some attempts in the literature to develop a more inflected view of consumption communities, for example in recognising their dynamic quality (McAlexander, Schouten, and Koenig 2002). But there 
is still much to be done in trying to articulate the complexities of what is going on in communal consumption in a context such as performing arts.

Peforming arts audiences demonstrate the three essential characteristics of community identified by Muniz and O'Guinn (2001): shared consciousness; rituals and traditions; and a sense of moral responsibility. These manifest themselves in a number of different ways, but examples of each respectively might include some familiarity with musical repertoire, observing dress codes or performance conventions, and showing (and expecting) respect for performers and other audience members. There is also a sense in which, at least for some of the audience, their joint consumption has the purpose of reinforcing a personal sense of community within the social order of 'small worlds' (Gainer 1995). Gainer's research looks at the way opera audiences use attendance at a performance as a social resource against uncomfortable change. But such benefits are not art-form specific - for example, Henry and Caldwell examine how heavy metal fans use concert attendance to achieve a "combination of collective bonding and the reinforcement of shared values that are perceived as superior to the mainstream' $(2007,171)$. Consumption of community as self-affirmation against an uncongenial social order elsewhere has parallels with other forms of community-oriented consumption. An example is older consumers' patronage of farmers' markets (Szmigin et al. 2003).

A sense of history is never far from discussions of community. The shared knowledge, rituals and traditions which characterise community are clearly dependent on members' shared sense of a past (even a relatively recent one). The passage of time is, of course, central to the experience of music. As has been noted by a number of writers, music has 
particular power to evoke memory in its hearers - a quality which explains its popularity with marketers and advertisers (Kellaris and Cox 1989; Baumgartner 1992). One might therefore expect time and memory to be of particular importance to how a classical music audience might experience itself as a consuming community - a further source of complexity in trying to envisage the processes involved.

Thus we can augment the relatively simple models of community consumption currently available from the literature with two new dimensions - the presence of service performers within the community, and the element of time. Memory activates the community's shared knowledge, tradition and mutual responsibility. Imagination, fundamental to the maintenance of community since Medieval times (Anderson 1983), conjures a sense of the future. And the picture is further enriched (or complicated) by the different levels on which camaraderie (the horizontal relations between community members) and communality (the vertical relations between consumers and providers) can operate.

Turner (1974) offers a helpful perspective on how we might develop the idea of community to provide a more adequate model of communal consumption. He differentiates between two forms of social interrelatedness (which can, in fact, be present at different times in the same group). On the one hand is 'structure' --- which, for Turner, is about roles, status and hierarchy 'consciously recognized and regularly operative in a given society' (1974, 237, original italics). Turner contrasts this with the notion of 'communitas', a necessarily temporary state where roles and individualities are subsumed 
All together now: A symphony orchestra audience as a consuming community

in a 'spontaneously generated relationship between leveled and equal total individuated human beings, stripped of structural attributes' $(1974,202)$. Turner distinguished these states in his anthropological studies of rites of passage, seeing the process as a movement from structure, through a state of 'liminality' (the threshold from one world into another) where communitas is experienced by participants, to their emergence into a new structure.

The consumption communities conceptualised in the literature to date tend towards an understanding of relatedness in terms of producer-imposed structure. For example Muniz and O'Guinn recognise status hierarchies amongst members based on levels of commitment to the brand expressed by ownership and long-term investment. We can recognise in these kinds of distinctions the structuring principle of behavioural and psychographic segmentation, as marketing attempts to organise and subjectify groups of consumers. However, if we want to go further in our understanding of communities as consuming units themselves (rather than as collections of consumers), communitas (a state of togetherness which transcends, albeit temporarily, the social divisions which make us individual subjects of marketing) is a more relevant concept. Arnould and Price (1993) refer to communitas in their account of the pilgrimage-like aspect of white-water rafting viewed as an extraordinary service experience. By its nature communitas is a temporary state, and spontaneous rather than consciously willed. It can be planned for and facilitated, though neither captured nor guaranteed. It may even be momentary or episodic within an overall experience. As will be reported later in the paper, a similar riskiness is part of the peculiar appeal of live performance to audiences. 
It can further be argued that, of all event or art-forms, live music is a particularly apt focus for consumity. Bowman (1998) cites Attali $(1985,6)$ on the potential of music as a tool for "the creation or consolidation of a community, of a totality." Whereas Attali is writing from a specifically political viewpoint, other writers suggest that music's binding force summons an essential human response. Burrows (1990) claims that what makes human beings distinctive is their relation to sound, in particular its role in "creating the kind of sympathetic resonance essential to community" (Bowman 1998, 256). And this cohesive effect is not limited to audience, but to the other members of the ‘communality' (Goodwin 1996) - the performers themselves. Stubley (1996, 7, 8, cit. Bowman 1998, 294) argues that performance melts the boundaries which separate individuals, describing it as "an on-going tuning process in which the self is experienced as an identity in the making..." resulting in empathetic bonding between musicians (and by extension other listeners) "in which the other is experienced...as a potential I." This process augments the individual performer's (and thus listener's) experience into a community of both production and consumption, engendering " $a$ meeting of Is at the body-sound interface” (Stubley 1996, 13, cit. Bowman, 1998: 294).

\section{Methodology}

Data collection consisted of four group discussions about their concert-going experience with a sample of the audience of a UK Symphony Orchestra. This was supplemented by participant observation as an audience member of four performances 
All together now: A symphony orchestra audience as a consuming community

given by the full orchestra or different combinations of its members in a variety of settings across a period of six months. The choice of focus groups as a method was led by their capacity 'not to infer but to understand, not to generalize but to determine the range, not to make statements about the population but to provide insights about how people perceive a situation.' (Kreuger 1994, 34) This limits generalisability to the population as a whole, but some assurance of the representativeness of the views expressed was provided by comparing the demographics of the sample with those of the concert-going population of England (ACE 2004). Although the number of respondents was too small to be statistically significant, the comparison revealed a bias towards the 55 to 64-year-old age band, compared to the national average. The Symphony Orchestra's marketing department confirmed that this was in keeping with their perception of their audience's profile.

Recruitment was via an online questionnaire distributed by the Symphony Orchestra via a link embedded in its email newsletter to regular audience members. This yielded information about demographic characteristics such as age and ethnicity, and behavioural characteristics such as frequency and mode of attendance (e.g. if part of a group) at concerts. It resulted in 106 usable responses each of which indicated a willingness to participate in further research in response to the incentive of entry into a draw for free tickets. Interestingly, when contacted in connection with arranging interviews, few if any respondents had any memory of having completed the questionnaire. A possible objection to using an email questionnaire might be that it would reflect the profile of email users rather than concertgoers. However, differences between 
All together now: A symphony orchestra audience as a consuming community

internet users and the 'normal' population are now so minimal as to make apologies for accessing respondents via email somewhat redundant (Hewson et al. 2003). In the event, four focus groups took place involving 5, 4, 3 and 5 participants each. The number and size of interviews represents what was feasible within the time and resources available for the project, but allowed the inclusion of a range of experiences and attitudes. The use of a mixture of group interview and participant observation allowed some triangulation of data in order to build a more valid account of the subject under study than would have been the case using one method alone (Hammersley and Atkinson 1995).

The focus group discussions followed a schedule of stimulus questions which sought to isolate the 'group' aspect of audience experience. They were transcribed and analysed through first and second level coding (Miles and Huberman 1984; Strauss 1987) in search of regularities around the experiences described which would confirm or disconfirm the theoretical expectations I carried into the research from my literature review. Qualitative group discussions had the advantage of recreating some of the conditions of intersubjectivity and interaction which were of interest to the research project itself, revealing valuable insights into group norms surrounding audience experience.

The role of participant observation in the research was to experience the nuances of concert attendance concert at different times and in different settings in order to contextualise the interview data. Often respondents would refer to particular concerts or details of the auditorium or venue in illustrating a point, or reminding others in the group 
about particular incidents which had become part of the regular audience's folklore (for example a story about an elderly woman audience member being overcome during a performance during a recent season. The music, a particularly beautiful violin concerto played by an international virtuoso, had continued as those around her wondered whether to intervene). The woman in question had recovered, but the focus group members recalled how this sight had sparked fantasies about dying to music as they listened. Having a sense of the physical space in which such episodes might occur helped both in moderating and interpreting the group discussion. It also gave the researcher the opportunity to observe proximate members of the audience during performances, noting the effect (as far as could be judged) not only personally, but on other audience members, of their demeanour, posture, movement, or noise. A third function of participant observation was to gauge the diversity of the audience at first hand, admittedly unscientific though such an approach might be. There certainly was evidence of the predominance of older, white people at evening orchestral concerts (a major concern of respondents as we shall see) and at lunch time chamber or instrumental recitals (some of which occurred at a smaller venue near the main hall). On the other hand, a short, early evening concert aimed specifically at city centre workers on their way home, seemed to have succeeded in drawing a larger proportion of people in their twenties and thirties, but (perhaps because of daytime work commitments) rather soberly dressed, and, again. predominantly white.

\section{Findings and discussion}


All together now: A symphony orchestra audience as a consuming community

The main findings of the research fall into four main categories:

1. tension between (private) aesthetic and (collective) social experience at performances

2. an acknowledgement of shared moments of experience as points of access to the sublime (reflecting an approach to 'communitas')

3. evidence of the range of ways in which the presence of others mediates the experience of concert going

4. an emergent theme of 'lack' permeating much audience experience

\section{Private versus collective experience}

Participants tended to play down the social aspects of their concert attendance, stressing instead their personal connection to the music being performed rather than what they regarded as the peripheral aspects of attending the performance. As they talked, however, considerable ambiguity emerged around this claim:

I think it isn't particularly a social occasion. As it happens I go mostly with my subscription and just buy an odd ticket for my husband for a concert that I think he might like and not fall asleep in, because he tends to fall asleep. I do meet up with two friends who have also got a subscription, but it's not particularly a social occasion (Female, $55-64)$

Other participants in this discussion were quick to confirm that they, too, did not see concerts primarily as 'social' occasion. Yet social aspects also emerged in their accounts to conflict with their conscious insistence on the primacy of personal experience. 
Reflecting on this has led me to interpret these responses as resistance to what participants saw as the orchestra's inappropriate marketing of concerts as programmatic 'social' experiences, rather than respecting their absolute autonomy as music. It became clear early in the first interview that participants had assumed I was working directly for the orchestra (in spite of the information I had supplied in obtaining their informed consent) and saw the discussion as an opportunity to share some quite specific concerns related to what they perceived as a crisis in audience numbers. In spite of my reiteration of the independence of the research project (other than a commitment to sharing my findings with the orchestra) in this and subsequent groups, this remained a constant subtext to the discussions - a form of slightly antagonistic 'communality' whereby I became a vehicle for a number of anxieties held by respondents.

On the other hand, there was also a sense in which by insisting on the individual character of concert-going, respondents were defending the personal psychic space which emerged as central to their motivation for attendance. Probed about how other performing art forms compared to music in terms of their social dimension, a number of respondents expressed a preference for music over theatre on the very grounds of the privacy, autonomy and even voluntariness of musical experience:

...if you want to go to a musical thing you can listen as hard or not as you want. You can switch off, if you're not in the mood, if you switch off you're not going to lose the whole plot, whereas in the theatre you might (Female, $44-55)$ 
All together now: A symphony orchestra audience as a consuming community

All respondents saw concert-going as entry into protected time and space outside normal experience. The characteristics of the venue were important here, as were the ritual aspects of sitting in the same seats on a particular night of the week available to certain subscribers. A sense of liminality extended to the nature of the live experience itself. From different respondents, and with reference to separate aspects of live performance, a sense of the 'sacred space' of performance emerged. Some talked in terms of the risk involved, some of the superhuman skill of the performers, some in terms of what live performance makes uniquely available as a heightened state of perception:

...watching a live performance highlights things that I'm not aware of on a CD. You think, gosh, what happened then, I never realised, to see the actual physical movement that makes a sound is very powerful (Male, $44-55)$

Another respondent linked this specificity of live performance with a sense of active communality with the performers, as if what is being performed is less important than the fact of its performance by real people (perhaps an instance of the link being more important than the thing (Cova 1997)):

I like hearing live music, and I wouldn't say I've stopped buying CDs; I've stopped trying to find the definitive performance of bits of music I like. I just like to go and hear the Symphony Orchestra because it is what it is on the nights, and it's real people playing, so it's not passive [Interviewer: yeah] for me, you know... It's nice to go and listen properly. (Female, $44-55$ ) 
Later in the same discussion three of the participants likened the experience of regular concert-going to supporting a football team: "the same group of people run out on to the pitch every week; the same group of people come out on to the platform every week..." One of the anxieties which participants attempted to channel through me back to the orchestra's management concerned unexplained comings and goings on the platform, particularly what they saw as the orchestra's slowness to make a permanent appointment to a key position.

Thus, while the integrity of a personal musical experience is of central value to classical music audiences, the social aspect of its production, at least in terms of communality with the musicians, is inseparable from it.

I think it's something to be proud of to have them as people, that we have a proper orchestra, in that sense. (Female, $24-35$ )

...you get to know the individual player, the person, you feel as though you do. (Female, $64-75$ )

\section{Shared moments of experience as access to the sublime}

...I think there was a slightly different audience dynamic than sometimes...[Interviewer: An audience dynamic; how might that manifest itself?] There was a more tangible sense of encouragement in not just the applause in terms of volume and so on, but a sense of....different kind of audience (Male, 34 - 45) 
All together now: A symphony orchestra audience as a consuming community

This statement revealed how the audience can allow something special to happen by behaving in a unified, but spontaneous, way. The concert in question was by a local youth orchestra and had been the focus of intense goodwill by the audience (motivated by bonds of kinship, or perhaps just regional pride) to spur the performers on to a sublime performance. The reported experience had signs of communitas, a form of experience whose quasi-religious characteristics did not go unremarked by the participants:

The other thing is that having been brought up a Catholic I used to go to church, and I think there is some kind of sacred, quasi-religious dimension to this, which we haven't really explicitly spoken about, but perhaps it's been explicit [overtalking] (Male, 34 - 45)

...when they take the whole audience with them, which doesn't happen all the time, but you know when it does happen, that feeling, that everyone's feeling the same thing, and you can hear a pin drop. (Female, $44-55)$

The sublime is, however, difficult to verbalise. Respondents saw silence as an appropriate way of sharing what had been experienced together in such moments of communitas:

...then we go on for a meal, we don't talk about what we've heard, or what the concert's been like, but it's a really nice atmosphere, just wandering across and having a meal, and just talking about other things...(Female, $44-55)$

As mentioned in the previous section, some maintained that their motivation for attending concerts rather than, for example, theatre, was the avoidance of words altogether - 
All together now: A symphony orchestra audience as a consuming community

preferring an art form which did not demand continuous cognitive engagement with a verbal text, but allowed lapses of attention or reverie during the performance. Non-verbal engagement promoted a sense of camaraderie with other audience members: "just a sense that people have been to a concert that's fine, that's what you want to happen, silence rather than an intense dialogue with someone" (Male, $34-45)$.

The focus groups thus provided evidence of shared moments of consumity akin to 'flow' experience (Csikszentmihalyi 1990) which, while valued as real and highly significant to the essence of concert-going, evaded verbal formulation.

\section{Evidence of the range of ways in which other audience members mediate experience}

Participants' frequent insistence on the private nature of musical experience would imply that interaction by audience members in the context of performance could only have a negative effect. This theme was enthusiastically espoused by a group who swapped horror-stories of the distractions which other people could provide - from overpowering after-shave and perfume, to the unpleasant proximity of obese neighbours, noisy page-turners, hummers, finger or foot tappers and coughers. My participant observation at concerts confirmed that the body language of even perfectly silent audience members can be a distraction (for example, restlessness or feet movement) or can actually promote one's own attention to a performance through creating a general orientation of encouragement and respect for the performer. One respondent saw the issue as part of life's rich tapestry: 
I have to cope with a chap who tends to snore that sits [laughter], who at the end jumps up and shouts ‘Bravo! Bravo! (Male, 64 - 75)

Those in the group who had experience of concert going in the USA pointed out that persistent conversation appeared to be accepted there as the norm ("It's a very English thing, to be well-behaved"), but participants across the groups argued that concert-going conventions in the UK were excluding younger or more diverse audiences.

On the other hand, the issue of initiating new audiences into the experience of classical music framed what many respondents acknowledged as the positive impact of other people on their concert going. A common biographical theme emerged whereby a particular individual in a respondent's life (a family member or a teacher) had lit the respondent up with their own enthusiasm and illuminated a new world of experience - an illustration of the pervasive presence of memory in music. On the other hand, the process of socialisation into being good concert-goers was generally admitted to be less inspirational:

My dad took us to things when we were little and then killed us if we misbehaved [overtalking, laughter]..my brother would have, when he was young, learned sort of boredom strategies, because I know he used to sit and count bricks and things on the wall when he got bored... (Female, 24 35) 
All together now: A symphony orchestra audience as a consuming community

For some participants, the presence of knowledgeable others at a performance (even in the form of 'professional' others such as pre-concert talks givers) was seen as a considerable benefit in their own continued initiation into unfamiliar experiences:

That's why I like a season ticket, because there's a good feeling, we know each other, we talk about the performance, and it's quite an experience. I quite enjoy, particularly listening to what knowledgeable people have heard, because I can go along, and say, well I thought that was, and sometimes I go along and hear a lot of notes, but to me there wasn't much music there. And to the experts, perhaps that was really a fine performance. (Male, $64-75$ )

In summary, the focus groups, confirmed by participant observation, suggest that audience members perceive what they 'do' at performances as facilitating each other's experience by remaining unobtrusive: “you don't want participation during the music, you just want absolute stillness around you" (Female, $54-65)$. Respondents were quick to note the distractions which other audience members can place in the way of individual enjoyment of a performance, but reflected uncomfortably that the conventions of good behaviour at concerts were a contributory factor to the exclusion of new audiences - a theme developed in the next section. There was a paradoxical acknowledgement, however, of the contribution which other people make through their enthusiasm and expertise, as well as the power of shared moments of experience in accessing the sublime.

\section{A sense of 'lack'}


All together now: A symphony orchestra audience as a consuming community

A frequently-reported adverse effect of other people was simply their absence either as fillers of an auditorium where the impact of the music would be more powerful in a capacity house "if the hall's half-empty, I think, all those poor people who haven't come in; They're missing all this. Why? Where are you?" (Female, $44-55$ ); or as replacements for the ageing audience base:

I look at it and I despair, really, because of the audience, because although I'm having a lovely time, it's so middle-class, middle-aged, old and white, and I wonder what is going to happen when we all pass on? Who's going to, what's going to ... Who's going to fill that hall? (Female, 54 - 65)

This exasperation at the lack of younger or more diverse audience members was a subject to which all of the groups returned (indeed the expectation of many of the participants was that any audience research carried out in connection with the Symphony Orchestra should necessarily be oriented towards this issue). It provided a constant back-drop to their experience of concert-going ('having a lovely time' while in 'despair'), and contributed to a shared narrative of decline in educational and civic norms (for example the exclusion of classical music from television programmes and its demotion in educational provision in general). An additional layer of complexity was provided by the simultaneous desires to see new audiences and preserve traditional forms of presentation which a number of participants voiced during the groups. One respondent objected vigorously to the pomposity surrounding performance conventions, yet a moment later rejected the orchestra's marketing tactic of giving concerts themed titles: 
All together now: A symphony orchestra audience as a consuming community

It's crass I think... 'Unchained Melody' [drawls] Tchaikovsky's Violin Concerto in the first half, I don't think so, and Romeo and Juliet in the second half. It's so... [tails off in disgust] (Male, 54 65)

As well as the perceived absence of new audiences to replenish declining attendance, there was a more personalised sense of lack related to friends and family who were either deceased or too frail to attend. Playing down the social side of concert going, one participant explained that: "It used to be because the group along our row, about eight people who had been going for years, so we met each other, but gradually through death and illness it's reduced but I don't see it as a social occasion" (Female, 54 - 65)

Thus the consumity at any concert is haunted by memories of those no longer present (perhaps evoked by particular works or composers) and harrowed by the absence of those who they feel should be there but are not, the imagined community who are elsewhere - a lost generation:

...we talk about this as though it's an age thing, but we've all just sat round the table, and said we started 30 years ago, so we weren't our age when we [overtalking] (Female, $44-55$ )

This feeling of conflictedness, of a simultaneous consciousness of the need to change the way things are, alongside a reluctance to abandon the past, is encountered in many mature markets surrounded by environmental turbulence. There is recognition of the need to access new markets in order to survive, but unwillingness to relinquish familiar territory in doing so. The solution offered by accepted marketing wisdom tends to be a 
All together now: A symphony orchestra audience as a consuming community

combination of innovation and segmentation. I reflected during the focus group

discussions that the extensive outreach work which the Symphony Orchestra conducts

had passed its traditional audiences by (a testament, perhaps, to focused targeting). As

mentioned earlier, my participant observation provided some evidence that different

performance formats were having some effect in reaching different audience groups. Yet

the anxious good will manifested by all the groups suggested itself as a potential resource

for reaching new audiences through some kind of co-optation strategy.

\section{Conclusions}

The evidence from this research suggests that the communal aspect of audience experience is an important and distinctive feature of arts attendance, but that it is more complex and inflected than current notions of consumption communities acknowledge. In particular, it reveals the importance of the temporal, imaginative element of how audiences experience performances (and themselves) which includes those who are absent as well as those who are present at a performance. With regard to those who are present, current models underplay the importance of the role of communality (i.e. provider/consumer relationships) in the overall sense of community experienced by an audience.

This has a number of implications for arts marketers. Perhaps the most important is to reframe how audience experience is understood in terms of imagined and actual community. There needs to be a refocusing on the biographical aspect of arts experience 
All together now: A symphony orchestra audience as a consuming community

- how it aligns with the life stage of audience members both individually and collectively. This has practical consequences for how music (or other services) are packaged and promoted, with an emphasis on what Cova (1997) calls 'ethno marketing', in other words a more holistic attention by marketers to the lifestyle of consumers, or on what Baumgartner (2002) calls the 'personology' of the consumer. In practical terms this is likely to result in greater use of visual rather than verbal communication to articulate product benefits, promotional emphasis on joint consumption (co-opting existing consumers rather than by-passing them in what may be overly exclusive segmentation strategies), and facilitation of the benefits of becoming part of the audience community through attention to distribution elements of time and space.

Interestingly, recent UK policy literature on making the arts more relevant to diverse audiences has placed a great deal of emphasis on the importance of social aspects of attendance at events or venues - both for for black and minority ethnic audiences (Jermyn and Desai 2000) and for economically-disadvantaged audiences (FreshMinds 2007). The current emphasis is on reframing what is on offer in terms which are likely to motivate a wider range of attendance: 'a focus on making cultural activities social activities or experience is perhaps the most effective [tactic] of all' (FreshMinds 2007, 12). The advice extends not only to repositioning the arts offering itself as a more social experience, but to the choice of promotional and distribution channels which leverage the power of social networks to open doors into constituencies currently under-represented in concert halls and auditoria. It can be tempting to invoke negative stereotypes of classical music, along with other 'institutionalised' art forms as 'irrelevant, old-fashioned, 
somebody else's' (Francis 1990, cited in Bridgwood, et al. 2003, 20). But in spite of the apparent barriers of tradition and convention which continue to surround it, the social dimension which has emerged from this research as integral to the experience of live music has considerable untapped potential in connection with both its repositioning and its promotion to new audiences.

Furthermore, the powerful communality and sense of personal history displayed by participants reveal distinctive opportunities for income development by arts organisations. Individual giving schemes aimed at resourcing particular orchestral positions are one possibility, perhaps enhanced by training bursaries or studentships in particular instruments. Parallel to this, and reflecting the camaraderie dimension of communal consumption (and its context of personal history) is the opportunity for 'in memoriam' gifts and legacies as a development income stream that offers organizations and patron/donors lasting mutual benefit in establishing the ultimate imagined community - that of posterity.

(6744 words) 


\section{REFERENCES}

ACE. 2004. Arts in England 2003. Attendance, Participation and Attitudes. London: Arts Council England.

Anderson, Benedict. 1983. Imagined Community. London: Verso.

Armstrong, Arthur and Hagel, John. 1996. The Real Value of Online Communities. Harvard Business Review 74 (3): 134 - 41.

Arnould, Eric J. and Price, Linda L. 1993. River Magic: Extraordinary Experience and the Extended Service Encounter. Journal of Consumer Research 20(1): 24 - 46.

Arnould, Eric J. and Thompson, Craig J. 2005. Consumer Culture Theory (CCT): Twenty Years of Research. Journal of Consumer Research 31(4): 868 - 82.

Attali, Jacques. 1985. Noise: The Political Economy of Music. Minneapolis: University of Minnesota Press.

Baumgartner, Hans. 1992. Remembrance of Things Past: Music, Autobiographical Memory, and Emotion. Advances in Consumer Research 19: 613 - 20.

Bohé, Astrid. 2007. Analyst Speak: Decision making should move from one to many. New Media Age, July 19: 10.

Boorstin, Daniel J. 1974. The Americans: The Democratic Experience. New York: Random House/Vintage Books.

Bowman, Wayne D. 1998. Philosophical Perspectives on Music. London: Oxford University Press. 
Bridgwood, Ann, Clare Fenn, Karen Dust, Lucy Hilton, Adrienne Skelton, Megan Skinner (2003) Focus on cultural diversity: the arts in England attendance, participation and attitudes Research Report 34. London: UK Film Council, ReSource, Arts Council England.

Burrows, David L. 1990. Sound, Speech and Music. Amherst: University of Massachussetts Press.

Clarke, John, Janet Newman, Nick Smith, Elizabeth Vidler and Louise Westmarland. 2007. Creating Citizen-Consumers: Changing Identities in the Remaking of Public Services. London: Sage.

Coppieters, Frank. 1981. Performance and Perception. Poetics Today 2(3): 35 - 38.

Cova, Bernard. 1997. Community and Consumption. European Journal of Marketing 31(3/4): 297 - 317.

Cova, Bernard and Stefano Pace. 2006. Brand Community of Convenience Products: New Forms of Customer Empowerment - the Case "My Nutella the Community". European Journal of Marketing 40(9/10): 1087-1105.

Csikszentmihalyi, Mihaly 1990. Flow: The Psychology of Optimal Experience. New York: Harper and Row.

Fraering, Martin, and Michael S. Minor. 2006. Sense of Community: An Exploratory Study of Us Consumers of Financial Services. International Journal of Bank Marketing 24(5): 284-306.

Francis, J. 1990. Attitudes among Britain's Black community towards attendance at arts, cultural and entertainment events: a qualitative research study. London: Networking Public Relations Ltd. 
FreshMinds. 2007. Culture on Demand: Ways to engage a broader audience. July. London: Department for Culture, Media and Sport.

Friedman, Monroe, Piet Vanden Abeele and Koen De Vos. 1993. Boorstin's Consumption Community Concept. Journal of Consumer Policy 16: 35 - 60.

Gainer, Brenda. 1995. Ritual and Relationships: Interpersonal Influences on Shared Consumption. Journal of Business Research 32: 253-260.

Goodwin, Cathy. 1996. Community as a Dimension of Service Relationships. Journal of Consumer Psychology 5(4): 387-415.

Granovetter, Mark S. 1973. The Strength of Weak Ties. American Journal of Sociology 78: 1360 - 80.

Hammersley, Martyn and Paul Atkinson. 1995. Ethnography Principles in Practice. 2nd ed. London: Routledge.

Henry, Paul and Marylouise Caldwell. 2007. Headbanging as Resistance or Refuge: A Cathartic Account. Consumption, Markets and Culture 10(2): 159 - 74.

Hewson, Claire, Peter Yule, Dianna Laurent and Carl Vogel. 2003. Internet Research Methods: A Practical Guide for the Social and Behavioural Sciences. London: Sage.

Jermyn, Helen and Philly Desai. 2000. Arts: what's in a word? Ethnic minorities and the arts. London: Arts Council England

Kellaris, James J., and Anthony D. Cox. 1989. The Effects of Background Music in Advertising: A Reassessment. Journal of Consumer Research 16(1): 113 - 18. 
Kozinets, Robert V. 1999. E-Tribalized Marketing?: The Strategic Implications of Virtual Communities of Consumption. European Management Journal 17(3): 252 - 64.

2002. The Field Behind the Screen: Using Netnography for Marketing Research in Online Communities. Journal of Marketing Research (JMR) 39(1): 61-72.

Kreuger, Richard. A. . 1994. Focus Groups: A Practical Guide for Applied Research. Newbury Park, CA: Sage.

Lasch, Christopher. 1991. The True and Only Heaven: Progress and its Critics. New York: Norton.

Leiss, Wiilliam, Stephen Kline and Sut Jhally. 1990. Social Communication in Advertising: Persons, Products and Images of Well-Being. London: Routledge.

Maffesoli, Michel. 1996. The Time of Tribes. Thousand Oaks, CA: Sage.

Malinvaud, E. 1972. Prices for Individual Consumption, Quantity Indicators for Collective Consumption. Review of Economic Studies 39(120): 385 - 401.

McAlexander, James H., Stephen K. Kim, and Scott D. Roberts. 2003. Loyalty: The Influence of Satisfaction and Brand Community Integration. Journal of Marketing Theory \& Practice 11(4): 1-11.

McAlexander, James H., John W. Schouten, and Harold F. Koenig. 2002. Building Brand Community. Journal of Marketing 66(1): 38-54.

Miles, Matthew B., and Michael A. Huberman. 1984. Qualitative Data Analysis: A Source Book of New Methods. London: Sage. 
Muniz Jr., Albert M., and Thomas C. O'Guinn. 2001. Brand Community. Journal of Consumer Research, 27(4): 412 - 32.

Oliver, Richard. L. 1999. Whence Consumer Loyalty? Journal of Marketing 63(4): 33 - 44.

Putnam, Robert D. 2000. Bowling Alone: The Collapse and Revival of American Community. New York: Simon \& Schuster.

Schouten, John W., and James H. McAlexander. 1995. Subcultures of Consumption: An Ethnography of the New Bikers. Journal of Consumer Research 22(1): 43 - 64.

Schutz, Alfred. 1932/1967. The Phenomenology of the Social World. Evanston, Illinois: Northwestern University Press.

Smith, Eliot R., Charles R. Seger and Diane M. Mackie. 2007. Can Emotions Be Truly Group Level? Evidence Regarding Four Conceptual Criteria. Journal of Personality andSocial Psychology 93(3): 431 - 46

Smith, Mark J. 1998. Social Science in Question. London: Sage.

Strauss, Anselm. L. . 1987. Qualitative Data Analysis for Social Scientists. Cambridge: Cambridge University Press.

Stubley, Eleanor V. 1996. Modulating Identities: The Play of Ensemble Performance (Being in the Body, Being in the Sound). Paper presented at Music Educators National Conference, Spring, in Kansas City, MO.

Szmigin, Isabelle, Sarah Maddock and Marylin Carrigan. 2003. Conceptualising Community Consumption: Farmers' Markets and the Older Consumer. British Food Journal 105(8): 542 - 50. 
All together now: A symphony orchestra audience as a consuming community

Turner, Victor. W. 1974. Dramas, Fields and Metaphors: Symbolic Action in Human Society. Ithaca, NY: Cornell University Press.

van Gennep, Arnold. 1960. The Rites of Passage. Chicago: University of Chicago

Press. 